\title{
OPTIMALITY TESTING IN STOCHASTIC AND HEURISTIC ALGORITHMS
}

\author{
Vaida Bartkutė ${ }^{1}$, Gražvydas Felinskas ${ }^{2}$, Leonidas Sakalauskas ${ }^{3}$ \\ 1, 2 Institute of Mathematics and Informatics, \\ Akademijos g. 4, LT-08663 Vilnius, Lithuania \\ ${ }^{3}$ Department of Information Technologies, Vilnius Gediminas Technical University, \\ Saulètekio al. 11, LT-10223 Vilnius-40, Lithuania \\ E-mail:1'vaidaba@one.lt,2razazis@splius.lt, ${ }^{3}$ sakal@ktl.mii.lt
}

Received 3 October 2005; accepted 4 January 2006

\begin{abstract}
In this paper we consider the application of order statistics to establish the optimality in stochastic and heuristic optimization algorithms. We suggest a method for the estimation of confidence intervals of minimum using order statistics which is implemented for optimality testing and stopping in stochastic approximation and Simulated Annealing algorithms. The efficiency of this approach is discussed using the results of application to continuous optimization and Bin-packing problem.
\end{abstract}

Keywords: order statistics, Monte-Carlo simulation, continuous optimization, Simulated Annealing, Stochastic approximation.

\section{Introduction}

The stopping problem is topical in stochastic and heuristic optimization algorithms. In this paper we consider the application of order statistics to establish the optimality in stochastic and heuristic optimization algorithms and to stop the algorithm when the confidence interval of minimum becomes less than admissible value. Statistical inferences on the maximal (minimal) value of a function are described by Zilinskas and Zhigliavsky [1], and the application of the extreme order statistics in the estimation of the location of the maximum of a regression function can be found in Chen [2].

\section{Method for testing the optimality by order statistics}

The optimization problem is (minimization)

$$
f(x) \rightarrow \min ,
$$

where $f: \Re^{n} \rightarrow \mathfrak{R}$ is a function bounded from below, $\min _{x \in \Re^{n}} f(x)=f\left(x^{*}\right)=A>-\infty,\left|x^{*}\right|<\infty$. Let this problem be solved by the Markov type algorithm providing a sample

$$
\mathrm{H}=\left\{\eta_{1}, \ldots, \eta_{\mathrm{N}}\right\}
$$

which elements are function values $\eta_{k}=f\left(x_{k}\right)$. We suggest a method for the estimation of confidence intervals of minimum according to order statistics when the number of iterations is finite. To estimate confidence intervals for minimum $A$ of the objective function it suffices to choose from sample $\mathrm{H}$ only $k+1$ order statistic: $\eta_{(0)}, \ldots, \eta_{(k)}$, where $k=k(N), \frac{k^{2}}{N} \rightarrow 0, N \rightarrow+\infty$ [1]. Then the linear estimators for $A$ can be as follows:

$$
A_{N, k}=\sum_{i=0}^{k} a_{i} \eta_{(i)}
$$

where $k$ is much smaller than $N, a_{0}, \ldots, a_{k}$ are some coefficients satisfying the condition

$$
\sum_{\substack{i=1 \\ k}}^{k} a_{i}=1 . \text { Let us consider simple sets of coefficients }
$$


Case I $a=\left(1+\frac{2 \alpha-1}{k+1}, 0, \ldots, 0,-\frac{2 \alpha-1}{k+1}\right)$

Case II $\quad a=\left(\lambda^{T} \Lambda^{-1} \lambda\right)^{-1} \Lambda^{-1} \lambda$

where $\lambda=(1,1, \ldots, 1)^{T}, \Lambda$ is the symmetric matrix which elements are as follows:

$$
\lambda_{i j}=\frac{\Gamma\left(\frac{2}{\alpha}+i+1\right) \Gamma\left(\frac{1}{\alpha}+j+1\right)}{\Gamma\left(\frac{1}{\alpha}+i+1\right) \Gamma(j+1)}, \quad(j \geq i)
$$

Case III $a=\Lambda^{-1}\left(\frac{\left(b^{T} \Lambda^{-1} b\right) \lambda-\left(\lambda^{T} \Lambda^{-1} b\right) b}{\left(b^{T} \Lambda^{-1} b\right)\left(\lambda^{T} \Lambda^{-1} \lambda\right)-\left(\lambda^{T} \Lambda^{-1} b\right)^{2}}\right)$

where $b=\left(b_{0}, \mathrm{~b}_{1}, \ldots, \mathrm{b}_{\mathrm{k}}\right), b_{i}=\frac{\Gamma\left(\frac{1}{\alpha}+i+1\right)}{\Gamma(i+1)}, \alpha$ is the parameter of distribution of extreme values. We examine a choice of this parameter for continuous optimization

$$
\alpha=\frac{n}{\beta},
$$

$\beta$ is the parameter of homogeneity of the function $f(x)$ in the neighbourhood of the point of minimum:

$$
\left|f(x)-f\left(x^{*}\right)\right|=O\left(\left\|x-x^{*}\right\|^{\beta}\right)[1,4] .
$$

Then two-side confidence interval of the minimum of the objective function is as follows

$$
\left[A_{N, k}-\varepsilon, A_{N, k}+\varepsilon\right]
$$

where $\varepsilon=k^{\frac{1}{\alpha}} \cdot\left(\eta_{(k)}-\eta_{(0)}\right) \cdot \sqrt{\frac{a^{T} \cdot \Lambda \cdot a}{\delta}}$.

The one-side confidence interval of the minimum of the objective function is as follows:

$$
\left[\eta_{(0)}-r_{k, \gamma} \cdot\left(\eta_{(k)}-\eta_{(0)}\right), \eta_{(0)}\right]
$$

$$
\begin{aligned}
& \text { where } r_{k, \gamma}=\frac{\left(\frac{1}{c_{k}}+1\right) \cdot\left(1-\gamma^{\frac{1}{k}}\right)^{\frac{1}{\alpha}}-1}{1}, \gamma \text { is the } \\
& 1-\left(1-\gamma^{\frac{1}{k}}\right)^{\frac{1}{\alpha}}
\end{aligned}
$$

confidence level.

The experimental research is a way of exploring the behaviour of stochastic and heuristic algorithms [5] and, thus, we investigate the implementation of the approach developed for several algorithms by computer modeling.

\section{Optimality testing in stochastic approximation}

Let us consider the application of this approach to $\underline{\mathrm{Si}}$ multaneous Perturbation Stochastic Approximation (SPSA). Assume that function $f(x)$ satisfies Lipshitz condition, $\partial f(x)$ is its generalized gradient, $g(x, \xi)$ is a stochastic gradient, $\operatorname{Eg}(x, \xi)=\partial f(x), E\|g(x, \xi)\|^{2}<\infty[6]$.

The smoothing is a standard way for the optimization of Lipshitz functions $[6,7]$. We consider a smoothed function

$$
\bar{f}(x, \sigma)=E f(x+\sigma \xi), \xi \sim p(\cdot),
$$

where smoothing density $p$ is Lipshitz function as well, $\sigma \geq 0$ is the perturbation parameter. Functions smoothed by this operator are twice continuously differentiable [6]. The gradient of the smoothed function may be expressed as follows:

$$
\bar{g}(x, \sigma)=E\left(\frac{(f(x+\sigma \xi)-f(x)) \cdot \partial \ln (p(\xi))}{\sigma}\right)
$$

and the stochastic gradient introduced:

$$
g(x, \sigma, \xi)=\frac{(f(x+\sigma \xi)-f(x)) \cdot \partial \ln (p(\xi))}{\sigma} .
$$

Let us introduce an optimising sequence:

$$
x^{i+1}=x^{i}-\rho_{i} \cdot g^{i}, \quad i=1,2, \ldots,
$$

where $g^{i}$ is the value of the stochastic gradient at point $x^{i}$, $\rho_{i}$ is a scalar multiplier, $\sigma_{i}$ is the value of the perturbation parameter in iteration $i, x^{0}$ is the initial point. This sequence used in the construction of sample (2) converges a.s. to the solution of the optimization problem under convergence conditions typical for Stochastic Approximation algorithms [6].

\section{Experimental results for stochastic approximation}

The proposed method was tested with functions: $f(x)=\sum_{j=1}^{n} a_{j}\left|x_{j}\right|^{\beta}+A$, where $a_{j}$ and $b_{j}$ are sets of real numbers, $\beta=1$. The coefficients of sequence (7) were chosen according to the convergence conditions [6]:

$$
\begin{aligned}
& \rho_{i}=\min \left(0.1 ; \frac{1}{i}\right), \sigma_{i}=0.1 \cdot \sqrt{\frac{(n+2)(n+3)}{n \cdot(n+1)}} \cdot \min \left(1 ; \frac{10}{i^{\varphi}}\right), \\
& \varphi=0.75 .
\end{aligned}
$$

The estimate of minimum $A$, one-side and two-side confidence intervals of minimum $A$ of the objective function, when coeficients $a$ in (3) are computed according to all the cases described above, are given in Tables 1 and 2.

The upper and lower bounds of the confidence interval 
Table 1. Experimental results of the one-side confidence interval

\begin{tabular}{|c|c|c|c|c|}
\hline \multirow{2}{*}{$\gamma=0.95$} & \multirow{2}{*}{$\begin{array}{c}\text { Estimate of } \\
A=0\end{array}$} & \multicolumn{2}{|c|}{ Confidence interval } & \multirow{2}{*}{$\begin{array}{c}\text { Probability of hitting } A \text { to } \\
\text { the confidence interval }\end{array}$} \\
\cline { 2 - 4 } & & Lower bound & Upper bound & \\
\hline $\mathrm{n}=2, \mathrm{n}=500$ & 0.000014 & -0.000036 & 0.0000275 & 0.954 \\
\hline $\mathrm{n}=4, \mathrm{n}=500$ & 0.000289 & -0.000569 & 0.0005355 & 0.946 \\
\hline $\mathrm{n}=6, \mathrm{n}=500$ & 0.001027 & -0.001879 & 0.001819 & 0.942 \\
\hline $\mathrm{n}=10, \mathrm{n}=500$ & 0.004488 & -0.005359 & 0.0070606 & 0.946 \\
\hline
\end{tabular}

Table 2. Experimental results of the two-side confidence interval

\begin{tabular}{|lc|c|c|c|}
\multicolumn{1}{|c}{$\mathrm{n}=2, \mathrm{~N}=500, \quad \gamma=0.95$} & I case & II case & III case \\
\hline Estimate of $A=0$ & & 0.00001516 & 0.0000034 & 0.0000011 \\
\hline Confidence interval: & lower bound & -0.0000709 & -0.0000692 & -0.0000719 \\
\cline { 3 - 5 } & upper bound & 0.00010118 & 0.00007596 & 0.00007743 \\
\hline Probability of hitting $A$ to the confidence interval & & 0.974 & 0.974 & 0.976 \\
\hline Confidence interval of the hitting probability: & lower bound & 0.9739746 & 0.9738111 & 0.975944 \\
& upper bound & 0.9927592 & 0.9927239 & 0.993871 \\
\hline
\end{tabular}

of the objective function minimum value are given in Fig 1. These bounds were estimated by Monte-Carlo method with the number of trials $N=500$, when the confidence level was $\gamma=0.95$ and the coeficients in (3) were calculated according to Case I. From the results of Tables 1 and 2 and Fig 1 we can see that formulas (5) and (6) approximate the confidence interval of minimum value rather well and that the length of the confidence interval decreases when the number of iterations increases.

Thus, using formulas (5) and (6), we can introduce the stopping rule for the algorithm, namely, the algorithm stops when the length of the confidence interval becomes less than admissible value $\varepsilon>0$. We can see the asymptotic behaviour of the stopping rule in Fig $2(e=0.5,0.2,0.1$, $0.05,0.02,0.01,0.005,0.002,0.001,0.0005,0.0002$, $0.0001,0.00005,0.00002,0.00001)$.

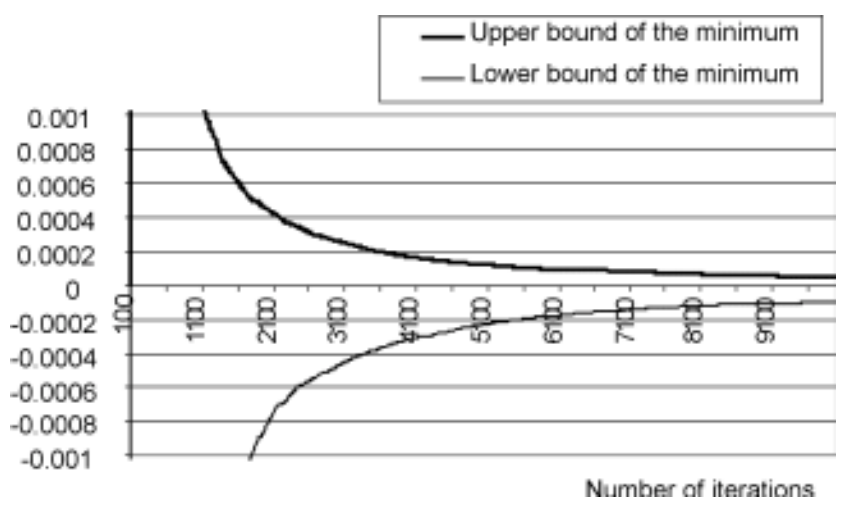

Fig 1. Confidence bounds of minimum $(A=0)$ $\gamma=0.95, n=2, N=500$

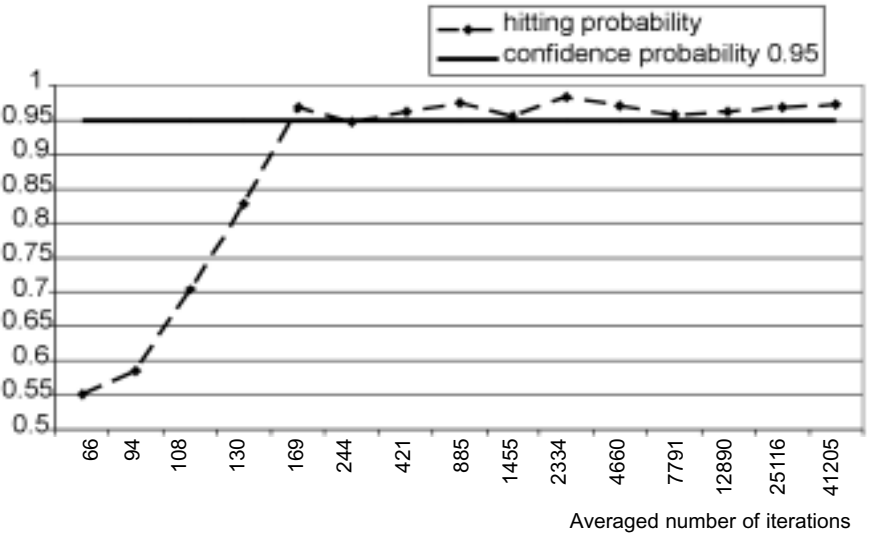

Fig 2. Asymptotic behavior of the stopping rule according to Case I, $\delta=0.95, n=2, N=500$

\section{Description of a simulated annealing algorithm}

Let us consider the application of this approach to continuous global optimization by a simulated annealing algorithm (SA).

The procedure of SA algorithm for solving problem (1) is described as follows [8].

Step 1. Choose initial point $x^{o} \in D \subset \mathfrak{R}^{n}$, initial temperature value $T_{o}>0$, a kind of temperature-dependent generation prob-ability density function, a corresponding temperature updat-ing function, and a sequence $\left\{\rho_{i} ; i \geq 0\right\}$ of monotonically decreasing positive numbers. Calculate $f\left(x^{o}\right)$. Set $i=0$.

Step 2. Generate random vector $z^{i}$ by using the generation prob-ability density function. If there exists $1 \leq j \leq n$ such that $\left|z_{j}^{i}\right|<\rho_{i}$, where $z_{j}^{i}$ is $j$-th component of vector $z^{i}$, repeat Step 2. Otherwise, generate new trial point $y^{i}$ by adding random vector $z^{i}$ to current iteration point $x^{i}$, 


$$
y^{i}=x^{i}+z^{i}
$$

If $y^{i} \notin D$, repeat Step 2; otherwise, calculate $f\left(y^{i}\right)$.

Step 3. Use the Metropolis acceptance criterion to determine the new iteration point $x^{i+1}$ [8]. Specifically, generate random number $\kappa$ with the uniform distribution over $(0,1)$, and then calculate probability $P\left(y^{i}, x^{i}, T_{i}\right)$ of accepting trial point $y^{i}$ as new itteration point $x^{i+1}$, given $x^{i}$ and $T_{i}$,

$$
P\left(y^{i}, x^{i}, T_{i}\right)=\min \left\{1, \exp \left\{\left[f\left(x^{i}\right)-f\left(y^{i}\right)\right] / T_{i}\right\}\right\} .
$$

If $\kappa \leq P\left(y^{i}, x^{i}, T_{i}\right)$, set $x^{i+1}=y^{i}$ and $f\left(x^{i+1}\right)=f\left(y^{i}\right)$; otherwise, set $x^{i+1}=x^{i}$ and $f\left(x^{i+1}\right)=f\left(x^{i}\right)$.

Step 4. If the prescribed termination condition is satisfied, then stop; otherwise, update the value of the temperature by means of the temperature updating function, and then go back to Step 2 .

The sequence $\left\{\rho_{i} ; i \geq 0\right\}$ of positive numbers specified in Step 1 of the above SA algorithm is used to impose a lower bound on the random vector generated at each iteration for obtaining the random trial point. This lower bound should be small enough and monotonically decreasing as the annealing proceeds. Since the temperature-dependent generation probability density function is used to generate random trial points, and since only one trial point is generated at each temperature value, SA algorithm considered is characterized by a nonhomogeneous continuous-state Markov chain. By applying the generation mechanism and the Metropolis acceptance criterion, SA algorithm produces three sequences of random variables. These are sequence $\left\{z^{i} ; i \geq 0\right\}$ of random vectors generated by the generation probability density function, sequence $\left\{y^{j} ; i \geq 0\right\}$ of trial points generated by (8), and sequence $\left\{x^{i} ; i \geq 0\right\}$ of iteration points deter-mined by applying the Metropolis acceptance criterion as described in Step 3. These three sequences $\left\{T_{i} ; i \geq 0\right\}$ of random variables are all dependent on temperature sequence determined by the temperature updating function.

The next conditions yield the global convergence property of the objective value sequence induced by SA algorithm as described above for solving problem (1) (see Theorem 1 in [8] ).

For $\omega>0, \lambda>0$, and $i>0$, let

$$
\begin{gathered}
D_{\omega}=\left\{x \in D \mid f(x)<f^{*}+\omega\right\}, \\
W_{\omega, \lambda, i}=\left\{x \in D \mid f^{*}+\omega \leq f(x)<f^{*}+\omega+1 / \iota^{\lambda}\right\} .
\end{gathered}
$$

Let $\mu(\cdot)$ denote Lebesgue measure on $\Re^{n}$, and $p\left(\cdot, T_{i}\right)$ denote the temperature-dependent generation probability density function used to generate random vectors. Assume that, for every $\omega>0, \mu\left(D_{\omega}\right)>0$ holds and there exist constants $\lambda>0$ and $R>0$ such that

$$
\mu\left(W_{\omega, \lambda, i}\right) \leq R / \iota^{\lambda} \text {, for all } i>0 \text {. }
$$

Then, for any initial state $x^{\circ} \in D$, sequence $\left\{f\left(x^{i}\right) ; i \geq 0\right\}$ of objective values converges in probability to the global minimum $f^{*}$ if temperature sequence $\left\{T_{i} ; i \geq 0\right\}$ determined by the temperature updating function tends to zero, as $i \rightarrow \infty$ and satisfies the following conditions:

$$
\sum_{i=1}^{\infty} \exp \left(-1 / \iota^{\lambda} T_{i}\right)<\infty
$$

$$
\begin{aligned}
& \max _{\substack{x, y \in D \\
y_{j}-x_{j} \mid \geq \rho_{i}, 1 \leq j \leq n}} p\left(y-x, T_{i}\right) \leq M_{1} / i^{\tau}, \quad \forall i \geq N, \\
& \min _{\substack{x, y \in D \\
y_{j}-x_{j} \mid \geq \rho_{i}, 1 \leq j \leq n}} p\left(y-x, T_{i}\right) \geq M_{2} / i, \quad \forall i \geq 0,
\end{aligned}
$$

where $N>0$ is an integer, $M_{1}>0$ and $M_{2}>0$ are constants, and $0<\tau<1$ satisfies $\tau+\lambda>1$.

These conditions indicate that under suitable conditions an appropriate choice of the temperature updating function ensures the convergence of SA algorithm to the global minimum of the objective function over the domain of interest.

The temperature updating functions are given below corresponding to different kinds of generation probability density functions to guarantee the global convergence of SA algorithm.

Temperature updating 1. Suppose that the assumptions described above hold. Let $r \in \mathfrak{R}^{n}$, with components $r_{j}=\max _{x, y \in D}\left|x_{j}-y_{j}\right|, \quad 1 \leq j \leq n$. Let $0<\lambda<1 / n$, $0<\rho_{0}<\min _{1 \leq j \leq n} r_{j}$, and $\rho_{i}=\rho_{0} / i^{\lambda / 4 n}$ for all $i \geq 1$, where $\left\{\rho_{i} ; i \geq 0\right\}$ is the sequence used to impose lower bounds on the random vectors generated in SA algorithm. Let the temperature-dependent generation probability density function $p\left(\cdot, T_{i}\right)$ be given by

$$
p\left(z, T_{i}\right)=\prod_{j=1}^{n} T_{i} / \pi\left(z_{j}^{2}+T_{i}^{2}\right), \quad z \in \Re^{n} .
$$

Then, for any initial point $x_{0} \in D$, sequence $\left\{f\left(x^{i}\right) ; i \geq 0\right\}$ of objective values converges in probability to global minimum $f^{*}$, if temperature sequence $\left\{T_{i} ; i \geq 0\right\}$ determined by temperature updating function satisfies the following condition:

$$
T_{i}=T_{0} / i^{1 / n}, i=1,2, \ldots
$$

where $T_{0}>0$ is the initial temperature value.

Temperature updating 2. Let $r \in \mathfrak{R}^{n}$, with components 
$r_{j}=\max _{x, y \in D}\left|x_{j}-y_{j}\right|, 1 \leq j \leq n$. Let $m \geq 1$ be an integer, $c>1,0<\lambda<\min \{c, m / n\}, 0<\rho_{0}<\min _{1 \leq j \leq n} r_{j}$, and $\rho_{i}=\rho_{0} / i^{\lambda \cdot m / c(m+1) n}$ for all $i \geq 1$, where $\left\{\rho_{i} ; i \geq 0\right\}$ is the sequence used to impose lower bounds on the random vectors generated in SA algorithm. Let the temperature-dependent generation probability density function $p\left(\cdot, T_{i}\right)$ be given by

$$
p\left(z, T_{i}\right)=\prod_{j=1}^{n} T_{i}^{1 / m} / 2 m\left[\left|z_{j}\right|+T_{i}\right]^{(m+1) / m}, \quad z \in \mathfrak{R}^{n} .
$$

Then, for any initial state $x^{0} \in D$, sequence $\left\{f\left(X^{i}\right) ; i \geq 0\right\}$ of objective values converges in probability to global minimum $f^{*}$ if temperature sequence $\left\{T_{i} ; i \geq 0\right\}$ is determined by the temperature updating function:

$$
T_{i}=T_{0} / i^{m / n}, i=1,2, \ldots,
$$

where $T_{0}>0$ is the initial temperature value.

Temperature updating 3. Let $r \in \mathfrak{R}^{n}$, with components $r_{j}=\max _{x, y \in D}\left|x_{j}-y_{j}\right|, \quad 1 \leq j \leq n, \quad d>1, \quad c>1$, $0<\lambda<c, 0<\rho_{0}<\min _{1 \leq j \leq n} r_{j}$, and $\rho_{i}=\rho_{0} / i^{\lambda / c \cdot n}$ for all $i \geq 1$, where $\left\{\rho_{i} ; i \geq 0\right\}$ is the sequence used to impose lower bounds on the random vectors generated in SA algorithm. Let the temperature-dependent generation probability density function $p\left(\cdot, T_{i}\right)$ be given by

$$
p\left(z, T_{i}\right)=\prod_{j=1}^{n}(a-1) / 2 T_{i}\left[\left|z_{j}\right| / T_{i}+e\right]\left\{\log \left[\left|z_{j}\right| / T_{i}+e\right]\right\}^{d},
$$
$z \in \mathfrak{R}^{n}$.

Then, for any initial point $x^{0} \in D$, sequence $\left\{f\left(x^{i}\right) ; i \geq 0\right\}$ of objective function values converges in probability to global minimum $f^{*}$, if temperature sequence $\left\{T_{i} ; i \geq 0\right\}$ determined by the temperature updating function satisfies the following condition:

$$
T_{i}=T_{0} \exp \left(-l \cdot i^{1 / d n}\right), i=1,2, \ldots,
$$

where $T_{0}>0$ is the initial temperature value and $l>0$ is a given real number.

The descriptions above indicate that a different form of the temperature updating function has to be used with respect to a different kind of the generation probability density function in order to ensure the global convergence of the corresponding SA algorithm. Furthermore, the flatter tail of the generation probability function implies the faster decrement of the temperature sequence determined by the temperature updating function.

\section{Experimental results for simulated annealing}

Experimental research is a way to explore the behaviour of stochastic and heuristic algoritms (Pardalos (2000)). The proposed method was tested with Beale functions:

$$
\begin{aligned}
f\left(x_{1}, x_{2}\right)= & \left(1.5-x_{1}+x_{1} \cdot x_{2}\right)^{2}+\left(2.25-x_{1}+x_{1} \cdot x_{2}^{2}\right)^{2}+ \\
& +\left(2.625-x_{1}+x_{1} \cdot x_{2}^{3}\right)^{2}
\end{aligned}
$$

where the search domain is:

$$
\mathrm{D}=\left\{-4.5 \leq x_{1} \leq 4.5,-4.5 \leq x_{2} \leq 4.5\right\},
$$

and global minimum point is: $\left(x_{1}, x_{2}\right)^{*}=(3,0.5)$ and minimum function value is $f\left(\left(x_{1}, x_{2}\right)^{*}\right)=0$.

The extreme value distribution parameter a was chosen according to the homogeneity rule (4). From Figs 3 and 4 we can see the estimate of minimum $A$, confidence bounds of this minimum value, the hitting probability to the confidence interval of minimum $A$ and its confidence bounds. The results presented in these pictures have been obtained using temperature updating 3. Similar results were obtained for temperature updating 1 and 2 .

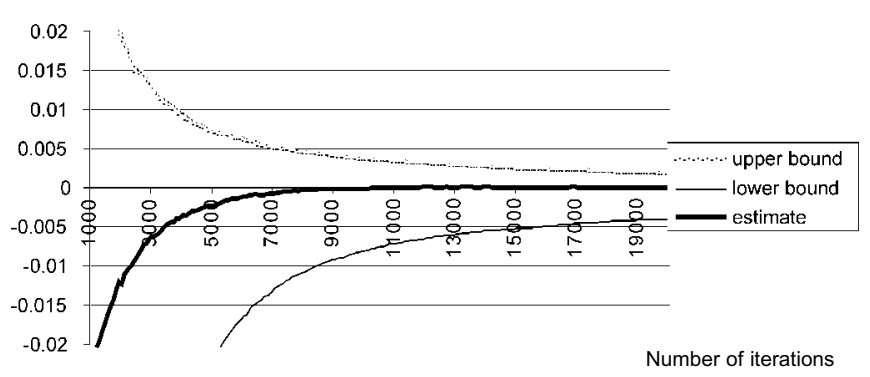

Fig 3. Estimate of minimum $A$

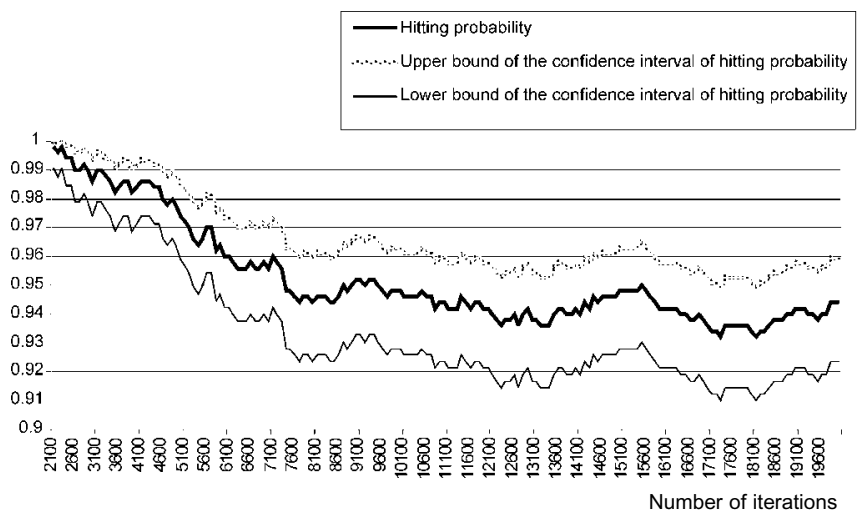

Fig 4. Confidence bounds of the hitting probability to the confidence interval of the minimum value and confidence level $\delta=0.95, n=2, N=500$

\section{Experimental results for Bin-packing}

Modification of the Simulated Annealing method described above was applied to Bin-packing problem.

The objective function was as follows:

$$
f(x)=\left|\sum_{i=1}^{n} x_{i} \cdot y_{i}\right|
$$

where $y_{1}, y_{2}, \ldots, y_{n}$ are real positive numbers, $x=\left(x_{1}, x_{2}, \ldots, x_{n}\right), x_{i} \in\{-1 ; 1\}$. Thus, set $D$ consists of vertices of the $n$-dimensional cube. 
The optimality testing approach was explored by MonteCarlo method. The objective function was minimized by SA method, where the numbers $y_{i}$ were randomly generated with uniform distribution $U(0,1)$ in each trial. Since in the latter case the value of $f(x)$ is asymptotically Gaussian, the extreme value distribution parameter $\alpha$ is equal to 1 .

In Figs 5 and 6 we can see the estimate of minimum $A$, confidence bounds of this minimum value, the hitting probability to the confidence interval of minimum $A$ and its confidence bounds as well. The results presented in these pictures have been obtained using temperature updating 1 .

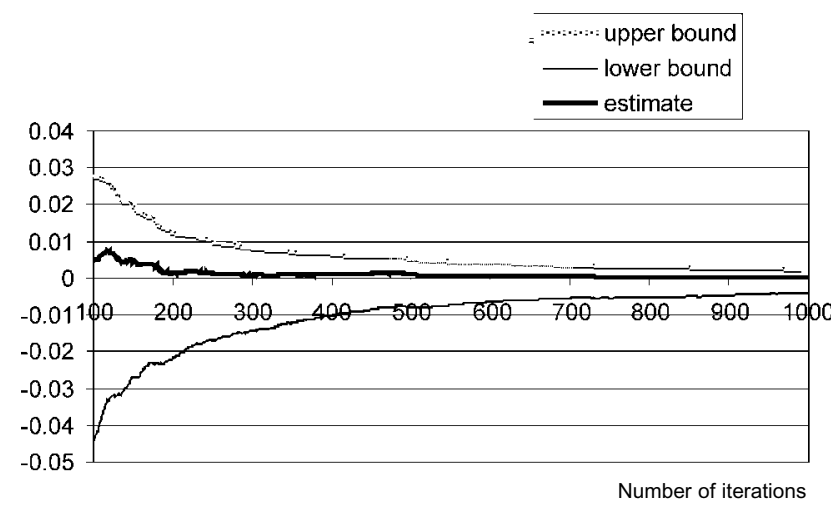

Fig 5. Estimate of the minimum value for Bin- packing

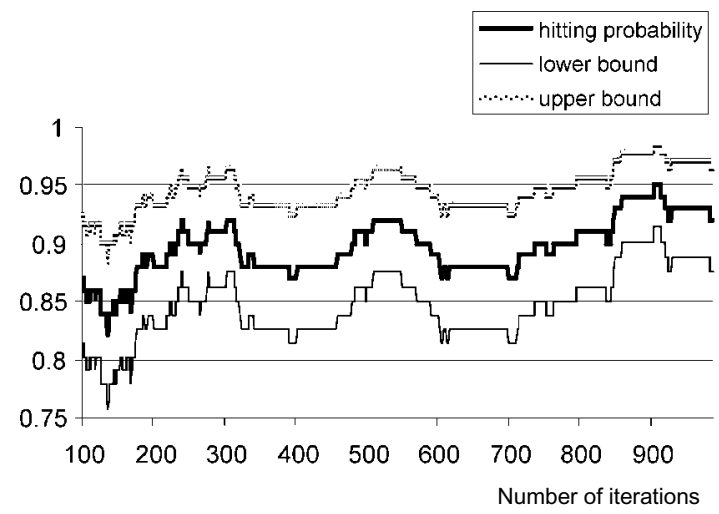

Fig 6. Confidence bounds for the hitting probability to the confidence interval of the minimum value and confidence level $\delta=0.95, n=15, N=100$
For comparison the real minimum value was established by the full selection of vertices $D$.

\section{Conclusions}

The linear estimator for the minimum value of function is proposed using the theory of order statistics and is studied in an experimental way. The estimators proposed are simple and depend only on the parameter of the extreme value distribution a. Parameter a is easily estimated using the parameter of homogeneity of the objective function or in a statistical way. Theoretical considerations and computer examples have shown that the confidence interval of the function minimum can be estimated with admissible accuracy when the number of iterations is increased. The stopping rule using the minimum confidence interval has been proposed and implemented in the Stochastic Approximation and Simulated Annealing.

\section{References}

1. Žilinskas, A.; Zhigljavsky, A. Methods of the global extreme searching (Методы поиска глобального экстремума). Moscow: Nauka, 1991 (in Russian).

2. Chen, H. Estimation of the Location of the Maximum of a Regression Function Using Extreme Order Statistics. Journal of Multivariate Analysis, Vol 57, 1996, p. 191-214.

3. Hall, P. On estimating the endpoint of a distribution. Annals of Statistics, Vol 10, 1982, p. 556-568.

4. Bartkute, V.; Sakalauskas, L. Order statistics for testing optimality in stochastic optimization. In: Proceedings of the 7th International Conference „Computer Data Analysis and Modeling”. Minsk, 2004, p. 128-131.

5. Horst, R.; Pardalos, P. M.; Thoai, van N. Introduction to Global Optimization. Nonconvex Optimization and its Applications, Kluwer Academic Publishers, Vol 48, 2000.

6. Bartkute, V.; Sakalauskas, L. Convergence of Simultaneous Perturbation Stochastic Approximation for Lipshitz functions. Lithuanian Mathematical Journal (Lietuvos matematikos žurnalas). No 44, 2004, p. 603-608 (in Lithuanian).

7. Clarke, F. H. Generalized gradients and applications. Trans. Amer. Math. Soc., Vol 205, 1975, p. 247-262.

8. Yang, R. L. Convergence of the Simulated Annealing Algorithm for Continuous Global Optimization. JOTA, Vol 104, No 3, 2000, p. 691-716.

\section{STOCHASTINIŲ IR EURISTINIŲ ALGORITMŲ OPTIMALUMO TYRIMAS}

\section{Bartkutė, G. Felinskas, L. Sakalauskas}

Santrauka

Sudarant stochastinius ir euristinius algoritmus, dažnai tenka spręsti algoritmų optimalumo testavimo ir stabdymo problemas. Statistines išvadas apie minimalią (maksimalią) funkcijos reikšmę galime rasti literatūroje (V. Bartkutė, L.Sakalauskas (2004); Žilinskas A., Žygliavskij A. (1991)). Šiame straipsnyje nagrinejamas pozicinių statistikų taikymas stochastinių ir euristinių algoritmų optimalumui tirti. Sudarytas metodas leidžia įvertinti minimalios reikšmės pasikliautinaji intervalą, naudojant pozicines statistikas, ir pritaikyti ši iverti optimalumui testuoti bei algoritmams stabdyti. Tarkime, turime seką $\mathrm{H}=\left\{\eta_{1}, \ldots, \eta_{\mathrm{N}}\right\}$, kurios elementai yra optimizavimo metu 
gautos funkcijos reikšmès. Noredami ịvertinti minimalios reikšmės pasikliautinaji intervalą sekoje $H$, išrenkame tiktai $k+1$ pozicinių statistikų (V. Bartkute, L. Sakalauskas (2004)). Kompiuterinio modeliavimo būdu tiriamas tikslo funkcijos minimalios reikšmès ịverčių taikymas stochastinès aproksimacijos ir modeliuojamojo atkaitinimo algoritmuose. Gautos teorinès išvados ir kompiuterinio modeliavimo rezultatai parodè, kad tikslo funkcijos ekstremalios reikšmès pasikliautinaji intervalą galima vertinti reikiamu tikslumu, kai iteraciju skaičius didejja. Straipsnio pabaigoje aptariamas šio metodo taikymas rūšiavimo (bin-packing) ir tvarkaraščiu sudarymo (schedulling) problemoms spręsti.

Pagrindiniai žodžiai: stochastiniai ir euristiniai algoritmai, optimalumas, pasikliautinasis intervalas.

Vaida BARTKUTE். Doctoral student. Department of Operational Reasearch. Institute of Mathematics and Informatics. First degree in applied mathematics, Kaunas University of Technology (1997). Master of Science (1999). Researcher in International Project "Critical thinking development in higher education", supported by Open Society Institute, New York, International Reading Association (Vilnius, Lithuania, 2002-2003). Research visits to International Centre of Theoretical Physics (ICTP) (Italy, 2004). Member of the European Working Group on Continuous Optimization since 2004. Author of about 10 scientific articles. Research interests: continuous optimization, extreme value theory, order statistics, Monte-Carlo method, optimal design.

Gražvydas FELINSKAS. Doctoral student. Department of Operational Research, Institute of Mathematics and Informatics. First degree (higher education) - in mathematics and informatics, Šiauliai Pedagogical Institute (1996). Master of Science (1997). Teacher and Assistant the Department of Informatics, Šiauliai University. Head of young computer users school, established in Šiauliai University. Research visits to Jyvaskyla University (JSS) (Finland, 2002), Hamburg University, Institute of Information Systems (Germany, 2004). Author of about 5 scientific articles. Research interests: continuous and discrete optimization, scheduling, stochastic heuristic search (Simulated annealing, Tabu search, genetic algorithms), extreme value theory, Monte-Carlo method, optimal design.

Leonidas SAKALAUSKAS. Professor, Doctor Habil. Department of Information Technologies, Vilnius Gediminas Technical University. Doctor (1974), Kaunas University of Technology. Doctor Habil (2000), Institute of Mathematics and Informatics. Professor (2005). Research visits to International Centre of Theoretical Physics (ICTP) (Italy, 1996, 1998). L. Sakalauskas is a member of the New-York Academy of Sciences (1997), vice-president of the Lithuanian Operation Research society (2001), Elected Member of the International Statistical Institute (2002), member of International Association of Official Statistic (2001), member of European Working Groups on Continuous Optimization, Financial Modelling and Multicriterial Decisions. Author of more 100 scientific articles. Research interests: continuous optimization, stochastic approximation, data mining, Monte-Carlo method, optimal design. 